\title{
Interpersonal justice and actual choice as ways of determining personal injury law and policy
}

\author{
David Campbell* \\ School of Law, Lancaster University
}

\begin{abstract}
Adapting the concept of 'interpersonal justice’ used by Professor Robertson to provide a 'meta-doctrinal' defence of the law of negligence, this article asks whether the personal injury system can be thought to have a democratic justification in common beliefs in such justice. It is widely acknowledged that the gross functional inadequacy of the personal injury system makes it implausible to claim that that system can be justified on grounds of compensation or deterrence. But that inadequacy makes it equally implausible to claim that common citizens would chose that system, which exists only because it is effectively compulsory. Constructing a market in first person insurance would put the existence of the personal injury system to the test of actual choice.
\end{abstract}

INTRODUCTION: PERSONAL INJURY AS A SYSTEM OF INTERPERSONAL

\section{JUSTICE}

To those, like myself, who are convinced that tort liability for personal injury ${ }^{1}$ should be abolished in countries such as the UK which aspire to have an adequate system of what I shall persist in calling social security ${ }^{2}$ against incapacity, ${ }^{3}$ academic commentary on

\footnotetext{
* I am grateful to Allan Beever, James Davey, Richard Lewis, Annette Morris, John Murphy, Andrew Robertson and the editor and his two anonymous reviewers for their comments.

${ }^{1}$ I will not discuss the law of other losses caused by negligence, but I will state that I believe that the argument of this paper can easily be extended to cover medical malpractice.

${ }^{2}$ I understand this term very broadly so as to include health services, social care, etc.

${ }^{3}$ I will not discuss, much less attempt to defend, social security provision, but it may help the reader if I say that my thinking on the issues discussed in this paper is based on Beveridge's principle of 'adequacy of benefit':

'The main feature of the Plan for Social Security is a scheme of social insurance against interruption and
} 
negligence now presents a mixed picture. On the one hand one can detect a welcome increased frankness about the, it must be said, deplorable state of negligence doctrine. One no longer feels one's views are entirely unusual when one maintains that the jurisprudential harm caused by the line of cases decided in the appeal courts between Anns v Merton LBC ${ }^{4}$ and Murphy v Brentwood $D C^{5}$ has not been confined to this or that 'principle', 'test', ‘framework' or whatever for determining the existence of a duty of care but has undermined the very idea that such determination is justiciable. Anns was perhaps the worst, ${ }^{6}$ but it was nevertheless but one, of a large number of cases the results of which were 'sanctified as core legal principles ... which finally must be overruled because their containment by distinguishing has become a farce' ${ }^{7}$ The point is that, as it is put in one of the best accounts of the existing law, 'the duty of care is determined entirely by policy ... and its putative principles are entirely illusory'. ${ }^{8}$

But, on the other hand, to the extent that this concession is made, it seems to be tolerable to those who broadly support the personal injury system because they base that support on what we might call 'meta-doctrines' of negligence which decouple the appellate law from the personal injury system’s acknowledged failings in respect of what had been regarded as its defining goals of compensation and deterrence. The success of the philosophy

destruction of earning power ... The scheme embodies six fundamental principles ... The fourth fundamental principle is adequacy of benefit in amount ... The flat rate of benefit proposed is intended in itself to be sufficient without further resources to provide the minimum income needed in all normal cases. It gives room and a basis for additional voluntary provision, but it does not assume that in any case': Sir William Beveridge Social Security and Allied Services (Cmd 6404, 1942) paras 17, 307.

${ }^{4}$ [1978] AC 728 (HL).

${ }^{5}$ [1990] 2 All ER 908 (HL).

${ }^{6}$ Perhaps a new dimension of unsatisfactoriness has been explored by Lord Hoffmann's recent admission that the decision in Fairchild v Glenhaven Funeral Services Ltd and Others [2002] UKHL 22; [2003] 1 AC 32 was flatly wrong: L Hoffmann 'Fairchild and After' in A Burrows et al (eds) Judge and Jurist: Essays in Memory of Lord Rodger of Earlsferry (Oxford University Press, 2013) 68. I understand that Lord Hoffmann had previously made this confession in a lecture given in Canada in May 2011 and subsequently published as 'Fairchild in Retrospect’ (2012) 39 Advocates Quarterly 257. I was not alone in regarding this decision as very costly nonsense when it was handed down, but for this reason as wholly unsurprising. I was very surprised by this admission by Lord Hoffmann.

7 J Getzler 'Patterns of Fusion' in P Birks (ed) The Classification of Obligations (Oxford: Clarendon Press, 1997) 191-2.

${ }^{8}$ A Beever Rediscovering the Law of Negligence (Oxford: Hart, 2007) 187. 
of corrective justice has turned the disregard of how the personal injury system actually functions which has long characterised abstract tort jurisprudence almost into a principle. ${ }^{9}$ The undermining of that philosophy which would seem to follow from showing, yet again, that the personal injury system normally does not, because it cannot, effect the posited correction is avoided in the theory of civil recourse's claim that the possibility of bringing a tort action is a redress mechanism which can be justified because its mere availability enhances social solidarity. ${ }^{10}$

In a recent number of this journal Professor Andrew Robertson has, on the basis of a major review of English and Canadian duty of care cases, ${ }^{11}$ made the latest contribution to his important attempt to add to this meta-doctrinal sort of line. ${ }^{12}$ In a sense, but only in a sense, conceding what I have said about the quality of negligence doctrine, Robertson seeks to nullify its destructive implications by arguing that they are confined to a relatively limited number of high level appeal cases which turn on what he calls 'community welfare’ policy considerations. ${ }^{13}$ Cases and reasoning of this sort, he argues, 'play a relatively minor role', indeed a 'marginal' role in England and Wales: 'while the ultimate appellate courts in the UK

\footnotetext{
${ }^{9}$ E Weinrib The Idea of Private Law (Oxford University Press, rev edn, 2012) ch 6.

${ }^{10}$ In respect of the specific issue addressed here see BC Zipursky, 'Civil Recourse, Not Corrective Justice' (2003) 91 Georgetown Law Journal 695) (and see also EJ Weinrib ‘Civil Recourse and Corrective Justice’ (2011) 39 Florida State University Law Review 273). The modern statement of this type of argument can be traced at least to Linden's claim that a proper law of tort 'helps to keep the peace ... because it permits an aggrieved person to recover money in court rather than to spill blood on the streets' (one of a number of rhetorically striking ways in which Linden framed this claim): AM Linden 'Auto Accident Compensation in Alberta: Toward Peaceful Coexistence’ (1968) 6 Alberta Law Review 219, 224.

${ }^{11}$ A Robertson 'Policy-based Reasoning in Duty of Care Cases' (2013) 33 Legal Studies 119. This argument must be put in the context of the general reflections on the role of policy in adjudication in A Robertson 'Contraints on Policy-based Reasoning in Private Law' in A Robertson and Hang Wu Tang (eds) The Goals of Private Law (Oxford: Hart, 2009).

12 On Robertson's views on the interesting, so far largely Australian, theory of 'civil peace', which also allows an argument that, even though it cannot be justified or even explained in terms of 'compensation, deterrence or standard setting ... by doing justice between individuals, the law of negligence serves a broader community welfare purpose ... the maintenance of civil peace': see A Robertson 'On the Function of the Law of Negligence' (2013) 33 Oxford Journal of Legal Studies 31, 42, 32.

${ }^{13}$ Robertson also does not believe that the fact that these cases have turned on policy considerations to the extent that they may be described as political in the pejorative sense necessarily has to lead to the chaos to which it unarguably has led, and in his paper in this journal he summarises an argument he has previously advanced for a change of approach that he believes would make such policy considerations justiciable: A Robertson 'Justice, Community Welfare and the Duty of Care' (2011) 127 Law Quarterly Review 370.
} 
... routinely take account of community welfare considerations, the lower courts in ...

England seldom do'. ${ }^{14}$ The great bulk of 'the day-to-day work of the courts on duty of care

questions ${ }^{15}$ is concerned with the articulation of what Robertson calls 'interpersonal justice':

While the courts are now commonly understood to make 'value judgments' instead of applying 'universal rules', the notion of interpersonal right and wrong remains the underlying idea. As Lord Atkin observed in Donoghue v Stevenson, the relevant legal standard is informed by commonly accepted ideas about the moral obligations that people owe one another, but is ultimately concerned to identify 'moral wrongdoing for which the offender must pay' ... Lord Atkin's characterisation of the relation that gives rise to an interpersonal responsibility to be mindful of the interests of others has proved, as a description, to be difficult to improve upon. ${ }^{16}$

I write this paper, not because I wish to address Robertson's argument in its own terms,${ }^{17}$ but because that argument has stimulated in me the thought that 'interpersonal justice' is, indeed, the fundamental issue we should consider when deciding whether the personal injury system should be abolished. For even if those taking my position in what is generally called the 'compensation debate' are correct that the personal injury system does not compensate or deter when evaluated on any of the criteria of economy, effectiveness or efficiency we normally use to decide whether investments of resources are justified, this would not ultimately matter if that system resulted from a sense of interpersonal justice rooted in common citizens' beliefs. I fully accept that, were this to be the case, the objections I have to the personal injury system, which I would continue to maintain were well-founded, would not ground abolition of that system. Democracy certainly trumps efficiency in my

\footnotetext{
${ }^{14}$ Robertson 'Policy-based Reasoning in Duty of Care Cases', above n 11, 121.

${ }^{15}$ Ibid.

${ }^{16}$ Ibid, 122; quoting Donoghue v Stevenson [1932] AC 562 (HL(SC)) at 580 (emphasis added by Robertson).

${ }^{17}$ No doubt the distinction between community welfare and interpersonal responsibility central to Robertson's argument is open to criticism for misrecognising abstract negligence liability principles (and, behind this, for its application of a broadly Dworkinian jurisprudence to these principles). I should make it plain that I myself find it generally unpersuasive, and the claim that foreseeability and proximity as they inform the neighbour principle are 'two considerations that clearly fall on the justice side of the line' (Robertson 'Policy-based Reasoning in Duty of Care Cases’, above n 11, 122), breathtaking. Having read all of Robertson’s cases from England and Wales, I have found it difficult to usefully separate them into his two classes. But I leave all this to those better versed in the formal law of negligence.
} 
view of politics and, as I trust will emerge from what follows, equating democracy and efficiency is the core of my normative economics.

Now, this thought about interpersonal choice does not directly reflect on Robertson's argument, which is meta-doctrinal in the strong sense that it is concerned with the policy ideas which inform negligence decisions when both specific considerations about community welfare and 'broad determinations as to what is just between the parties' are regarded as forms of policy. ${ }^{18}$ Indeed, that the state’s 'instrumental concerns' are pursued in terms of interpersonal morality at all is itself a matter of policy for Robertson. ${ }^{19}$ ' [T] $]$ he question is ... what standard of interpersonal conduct the state requires people to observe', ${ }^{20}$ and, of course, the state imposes its own standards about what harms it will recognise that do not entirely congruently map onto common beliefs; this indeed is the very burden of Lord Atkin's famous words:

acts or omissions which any moral code would censure cannot in a practical world be treated so as to give a right to every person injured by them to demand relief. In this way rules of law arise which limit the range of complainants and the extent of their remedy. The rule that you are to love your neighbour becomes, in law, you must not injure your neighbour' ${ }^{21}$

The strength of the link between what the state requires and what common citizens believe is a question which Robertson leaves open or indeed about which he is unconcerned in the work I am discussing. I must make it plain that I do not think this stance is tenable or that Robertson consistently maintains it. When he tells us that 'the relevant legal standard is informed by commonly accepted ideas', he is in my view conceding the necessity of some link to common citizens' beliefs, just as much as did Lord Atkin himself when, in the very act of distinguishing the neighbour principle from common beliefs he acknowledged that 'the

\footnotetext{
18 Ibid, 121.

${ }^{19}$ Robertson, above n 12, 42.

${ }^{20}$ Robertson 'Policy-based Reasoning in Duty of Care Cases', above n 11, 121.

${ }^{21}$ Donoghue v Stevenson, above n 16, 580.
} 
liability for negligence ... is no doubt based upon a general public sentiment of moral wrongdoing for which an offender must pay’.22

But I put this to one side as it is also not an issue which I wish to address. I wish, somewhat against Robertson’s intention, to regard the concept of interpersonal justice as a claim that a common belief that there is a class of moral wrongdoing for which the offender must pay is the source of legitimacy of the personal injury system. I am spared the problem of determining the precise strength of this claim for I believe it has no strength whatsoever. I will argue that the personal injury system as it actually, because necessarily, functions gives tantamount to no effect to this belief. I will then argue that a way of ascertaining common citizens' views about a correct policy towards personal injury is readily available, or rather, would be readily available save that using it requires the abolition of the personal injury system.

\section{WHAT DO WE THINK IS INTERPERSONALLY JUST?}

As I have said, I will regard interpersonal justice as a claim that it is commonly believed that there is a class of moral wrongdoing for which the offender must pay. Making this claim is dependent on separating negligence doctrine from an understanding of the way the personal injury system has been shown to function in the compensation debate. In the interest of brevity in discussing an issue most aspects of which have been very thoroughly canvassed indeed $^{23}$ and on which I have already had my say, ${ }^{24}$ I will merely state the principal points:

\footnotetext{
${ }^{22}$ Ibid.

${ }^{23}$ Published in 2001, T Baker 'Blood Money, New Money, and the Moral Economy of Tort Law in Action' (2001) 35 Law and Society Review 275 appeared too late for inclusion in D Harris et al Remedies in Contract and Tort (Cambridge University Press, 2002) ch 24. It is the only at all recent contribution which, in my opinion, does say something fundamentally novel about the operation of the personal injury system. I hope it goes without saying that I do not mean to disparage those contributions which either deal with new developments or which, like, indeed, Robertson's, have put forward a fresh way of looking at facts which are nevertheless now well known.

${ }^{24}$ Ibid. Non-pecuniary loss is discussed in this chapter. Quantification generally is discussed in chs 22-3 written by Roger Halson.
} 
(1) if 'must pay' is understood to mean effectively compensate the harm caused by the 'moral wrongdoing', then this is a most inaccurate account of the operation of the personal injury system, in which, leaving aside the hazards of establishing liability, the quantification of damages, a subject normally not discussed in the formal tort jurisprudence or the teaching of tort, always bears only a very weak relationship to compensation, and, in regard of nonpecuniary loss, no relationship at all;

(2) if by 'the offender' who must pay is meant a responsible individual, then this case is so rare that it can be put to one side as an exceptional state of affairs in descriptions of the working of the personal injury system. The real payers are insurance companies, overwhelmingly third party liability insurers, and almost all the remainder are large undertakings such as local authorities which self-insure by making provision for their liabilities from within their own budgets. Insofar as it is a matter of anything other than natural concern for one's own well-being and the well-being of others, optimisation of the levels of deterrence of the actions covered by the law of negligence is achieved, to the extent it is achieved, by the criminal law and regulatory sanctions;

(3) if it is claimed that 'moral wrongdoing' is ultimately identified by the views of common citizens, then this is to ignore the shaping of tort liability by the institutional structure of the personal injury system. The identification of a solvent tortfeasor is essential to the claims process, and, in a system dominated by liability insurance (as the personal injury system ultimately is bound to be unless insurance against negligence is forbidden, which would itself

In the subsequent decade, the principal change that has taken place has done something to confirm my observation that '[i]t is very hard to conclude that a system which cannot be made to run better without imposing a welfare loss is other than indefensible': (ibid 449). Changes in fee arrangements and in the handling and publicisation of the claims process has led to a worrying increase in motor accident claims which call the integrity of the claims process into doubt and are reflected in a serious rise in insurance premiums: House of Commons Transport Committee Fourth Report: The Cost of Motor Insurance, HC (2010-12) 591. (The Committee also published three follow up Reports, two of them Government responses to the Committee's findings, during the 2010-12 Session). 
lead to the disappearance of the system), the incidence of solvency is largely a function of the market conduct of the insurer;

(4) liability insurance dominates the operation of the law of negligence because negligence is not a voluntary system. It is essentially a system of compulsory indemnification of third parties by an insurer responding to the occasions and standards of mandatory liability set by the state, though the standards are principally set by the courts rather than directly by legislation. ${ }^{25}$ It is an anomaly in market economies in which economic goods are still principally allocated by voluntary contractual choices to exchange, with government expenditure playing a very important yet subsidiary role. In England and Wales, negligence must clearly be distinguished in its nature and effects, even in these days of privatisation and quasi-markets, from social security against incapacity.

In sum, though there are some aspects of damages which are compensatory and though liability may be borne by some individual tortfeasors, to describe the personal injury system as a system of compensation and of deterrence is akin to describing the Sahara as a wetland because there are oases in it. The point I am trying to make, however, is not that, as a deterrent of or as compensation for accidentally inflicted personal injury, much less as part of a social response to incapacity in general, negligence liability is almost entirely unfit for purpose, though I believe this is so. My point is that the shortcomings of the personal injury system not only make it wrong to believe that that system usefully contributes to the social response to incapacity or to the deterrence of undesirable conduct, but also make it wrong to believe that the law of negligence reflects the sense of interpersonal justice of common citizens. We must ask the following question outright: as negligence liability has no functional justification in terms of a social response to incapacity, does it have a democratic justification in the views of common citizens?

\footnotetext{
${ }^{25}$ The role of legislation in tort law has recently been most interestingly re-examined in TT Arvind and J Steele (eds) Tort Law and the Legislature (Oxford: Hart 2012).
} 
Let us go to the nub of the matter by concentrating only on the law of England and Wales, and only on non-pecuniary loss in personal injury cases. Though this is of course a restricted focus, I believe it is justified because it is, as a matter of law in action, what the personal injury system is overwhelmingly about. With Ms Morris, Professor Lewis has recently authoritatively surveyed what that system actually does, and quotation of the relevant part of their account, which rather depressingly is highly reminiscent of Lewis' previous accounts, will put the discussion on a proper footing:

financial loss comprises but a small part of the overall damages bill. Instead it is non-pecuniary loss that accounts for a disproportionate amount of damages. Pain and suffering and loss of amenity comprised two thirds of the total awarded thirty years ago, and it has remained at about that level. The extraordinary importance given to pain and suffering, as opposed to financial loss, reflects the fact that most awards are for minor injury and involve relatively small sums. The average payment is less than $£ 5,000$, which is approximately two months’ average salary. In these minor cases claimants suffer very little, if any, loss of earnings and rarely incur medical costs. Future financial loss occurs in only 7 per cent of cases and amounts to less than 9 per cent of the total damages bill. Where road accidents are involved, 70 per cent of the injuries in recent years have been attributed to the effects of whiplash. Claimants are then often left with symptoms which are difficult to disprove. In practice ... the claimants in tort who suffer catastrophic effects as a result of their accident are very unusual. Instead, nearly all suffer very minor injuries and soon make a full recovery. They are not left with any continuing ill effects. In most cases the accident does not even result in a claim for social security benefit. It is these minor injury cases which account for the extraordinarily high costs of the system compared to the damages it pays out ... the essential point to note ... is that the image of the tort system as caring for the immediate financial needs of mostly severely injured people in society is far from the reality. ${ }^{26}$

The overwhelmingly typical personal injury claim will, then, result in a small payment for non-pecuniary loss which it stretches credulity to argue is compensation of even that loss. Its quantum is irrational (save as determined by convention) and its payment fruitless. It is a windfall. One might argue that it is a solatium, but the point is that this is never given as the reason for the payment. If one gives concrete content to the 'payment for wrongdoing' that is actually made, it would, I suggest, be completely mistaken to claim that there is general

\footnotetext{
${ }^{26}$ R Lewis and A Morris ‘Tort Law Culture: Image and Reality’ (2012) 39 Journal of Law and Society 562, 576-7.
} 
consensus behind this. Maintaining that the personal injury system ultimately reflects the beliefs of common citizens could have plausibility only if one assumes that a finding of liability normally leads to a remedy in any sense of the word which conveys respect for the the values of security against incapacity and of legality. But this is precisely what one cannot assume. I submit that common citizens would not support the personal injury system if they were aware of what it does, which follows from the inevitable limits of what that system can do, for it simply cannot be described as a rational response to moral wrongdoing for which the offender must pay.

It may, of course, very well be the case that common citizens believe that the personal injury system deters and compensates, but, as it doesn't, and as belief in a proposition which is wrong is analytically distinct from a belief in the same proposition when it is right, the personal injury system cannot be grounded in interpersonal justice. A belief cannot be held for the same reasons when it is right and when it is wrong. When it is right, that is the reason it is held. When it is wrong, there must be another element of the belief, one that, mistakenly, leads to its being thought to be right. At issue here is what I have called 'a continuing, stygian, popular ignorance of what the personal injury system actually accomplishes or can accomplish' as an essential condition of the preservation of that system. ${ }^{27}$

This is, in my opinion, the indisputable core of sense in the in other respects very vexed claim that the personal injury system has been an important cause of the growth of an unwelcome 'compensation culture'. ${ }^{28}$ An explanation of why we have adopted the personal injury system cannot emerge from examination of the formal law of negligence, for that law does not even normally discuss the remedies the personal injury system actually provides,

\footnotetext{
${ }^{27}$ Harris et al, above n 24, 409.

${ }^{28}$ The value, or otherwise, of this concept is authoritatively reviewed in R. Lewis et al 'Tort Personal Injury Statistics: Is There a Compensation Culture in the UK?' (2006) 14 Torts Law Journal 158; A Morris, 'Spiralling or Stabilising? The Compensation Culture and our Propensity to Claim Damages for Personal Injury’ (2007) 70 Modern Law Review 349; A. Morris 'The Compensation Culture and the Politics of Tort' in Arvind and Steele (eds), above n 25 and Lewis and Morris, above n 26, 579-91.
} 
much less that system's failure to compensate or to deter. It must be based on an analysis of the process of legal emergence which gives the formal law of negligence the significance it has despite its failure to acknowledge its own actual consequences. I am not competent to put forward a legal history of this emergence, though I am aware and readily acknowledge that such a history shows the creation of much of negligence liability, largely prior to the establishment of the universal welfare state, to be perfectly justifiable at the time. ${ }^{29}$ I wish to show only that this history now necessarily involves eschewing the use of the market mechanism by which we normally identify the legitimate choices of common citizens about investments of resources.

\section{INTERPERSONAL JUSTICE, WELFARE ECONOMICS AND INSURANCE:}

\section{COERCION OR CHOICE?}

As I have observed elsewhere, criticism of the personal injury system which would lead to the universalisation of full compensation would be regarded as utopian were it agreed that the immense expansion of welfare provision which universal full compensation requires is a good thing, which it is not. ${ }^{30}$ The compensation debate in the Commonwealth which appeared entirely stalled because of this utopianism was revived by Professor Stapleton’s answering what the Pearson Commission had found to be the unanswerable question of what to put in place of the personal injury system. ${ }^{31}$ Stapleton's answer, ${ }^{32}$ from which she

\footnotetext{
${ }^{29}$ eg PWJ Bartip and SB Burman The Wounded Soldiers of Industry (Oxford: Clarendon Press, 1983) and PWJ Bartrip Workmen's Compensation in Twentieth Century Britain (Aldershot: Gower, 1987). But on the justifiability of the current position see R Lewis, 'Employers’ Liability and Workmen's Compensation: England and Wales’ in K Oliphant and G Wagner (eds) Employers’ Liability and Workers’ Compensation (Berlin: de Gruyter, 2012).

${ }^{30}$ Harris et al, above n 23, 461

${ }^{31}$ Lord Pearson (Chair) Report of the Royal Commission on Civil Liability and Compensation for Personal Injury (Cmnd 7054, 1978). The shortcomings of the Person Commission's findings were thoroughly exposed in DK Allen et al (eds) Accident Compensation After Pearson (London: Sweet and Maxwell, 1979).

32 J Stapleton Disease and the Compensation Debate (Oxford University Press, 1986) 178.
} 
famously resiled, ${ }^{33}$ but which Professor Atiyah has substantially affirmed for the UK, ${ }^{34}$ was

to do nothing, or, more precisely, to do nothing in addition to providing social security for

incapacity. One part of the claim that social security provision is justified is that it represents

the choice of common citizens expressed through a legitimate collective decision-making

procedure: representative democracy. Except in the sense that a collective decision of this

sort has not been taken to abolish it, ${ }^{35}$ and that therefore the courts and other public bodies

support its operation, ${ }^{36}$ the personal injury system cannot claim legitimacy in this way. What

legitimacy can this public/private hybrid claim?

It is here that reflection on interpersonal justice as I am regarding it seems to me to

indicate a way forward. If the ultimate point is to reflect the views of common citizens, it is

time to determine what should be done by actually consulting those views. Of course, this has

in a sense been done in opinion surveys which have shown considerable support for the

\footnotetext{
33 J Stapleton ‘Tort, Insurance and Ideology’ (1995) 58 Modern Law Review 820. The extraordinary implications of this very important article for the consideration of the actually existing relationship of personal injury law and liability insurance are criticised in R Lewis 'Insurance and the Tort System' (2005) 25 Legal Studies 85; J Morgan 'Tort, Insurance and Incoherence’ (2005) 67 Modern Law Review 384 and R Merkin 'Tort, Insurance and Ideology: Further Thoughts' (2012) 75 Modern Law Review 301. The whole subject has recently been extensively reviewed in R Merkin and J Steele Insurance and the Law of Obligations (Oxford: Oxford University Press 2013) nb ch 13.

${ }^{34}$ PS Atiyah 'Personal Injuries in the Twenty-first Century: Thinking the Unthinkable' in P Birks (ed) Wrongs and Remedies in the Twenty-first Century (Oxford: Clarendon Press 1996) and PS Atiyah The Damages Lottery (Oxford: Hart 1997). Atiyah's omission of motor accident insurance from his proposals on what he believes are grounds of practical politics, ibid, pp 185-8, is highly damaging to those proposals, in my opinion completely undermining them. Cf R Lewis 'No-fault Compensation for Victims of Road Accidents: Can it be Justified' (1981) 10 Journal of Social Policy 161.

${ }^{35}$ The closest the UK Parliament came to doing so was, of course, some 14 years after Donghue v Stevenson, when the Labour government which introduced the universal welfare state considered the possibility: Sir Walter Monckton (Chair) Final Report of the Departmental Committee on Alternative Remedies (Cmd 6860, 1946) para 25. The decision to retain the damages system, though in a form that was perhaps intended to lead to its withering away, divided the Committee, and was taken despite the Committee as a whole finding that: 'substantial advantages would be gained were it found possible to abolish the remedy by action and to substitute for it rights to benefits under national insurance'.

${ }^{36}$ In the provision of evidence about claims to insurance investigators, in the attempt to criminalise fraudulent claims, in the calculation of benefit payments in light of insurance claims, etc. The policy relationship between welfare legislation and tort is most perceptively analysed in R. Lewis 'Recovery of State Benefits from Tort Damages: Legislating For or Against the Welfare State' in Arvind and Steele (eds), above n 25. At 288 Lewis repeats the argument he has made many times about the principal way the state supports tort in the UK. Were it not for the existence of social security as a relatively effective way of dealing with incapacity caused by accident, which props up the relatively extremely ineffective way of doing so by tort, 'it is unlikely that the action for common law damages ... would have survived long into the twentieth century'.
} 
system. ${ }^{37}$ But, as with all such surveys, the opinions expressed in them beg the essential question, for they are merely abstract, being decoupled from the commitment of resources which gives them their meaning. To really base the decision about what personal injury system we should have, or whether we should have one at all, on the views of common citizens will require those citizens to make an actual choice based on them directly bearing (above a floor of social security against disability) the risk of harm from personal injury. This simply cannot be done by a law of negligence which gives rise to compulsory indemnity insurance. As it is, the very nature of the personal injury system means that common citizens are not linked to what Lord Atkin called payment, save in an almost negligible fashion. In order to explain what I mean, it is necessary to step back and say something about the concept of choice.

It is one of the claims essential to liberal market economics that there is something unique to the process of making an economic choice which those economics capture in a way superior to any other approach to choice. ${ }^{38}$ An economic choice is a choice about the allocation of limited resources which must involve an opportunity cost. The point I am trying to make is that such a choice must, as I have recently seen it graphically put, make the chooser squirm. ${ }^{39}$ Not all choices are like this. But one simply does not make an economic choice unless one includes the squirm factor.

One of the virtues of a market economy is that exchange by individual economic actors normally possesses the squirm factor, for those actors voluntarily commit an identified part of their limited personal resources to that exchange. Their being obliged to, as it were, tangibly back their choices will tend to promote an awareness of opportunity cost and a responsible attitude towards making those choices, though, of course, it does not necessarily do so. The

${ }^{37}$ Law Commission Damages for Personal Injury: Non-pecuniary Loss [1998] EWLC 257, appendix B.

${ }^{38}$ L Robbins The Nature and Significance of Economic Science (London: Macmillan, 2nd edn 1969) chs 1-3.

${ }^{39}$ EA Schmidt ‘The Missing Squirm Factor in Amartya Sen's Capabilities Approach' in SE Esquith and F Gifford (eds) Capabilities, Powers and Institutions (University Park, PA: Pennsylvania State University Press, 2010). 
sense of responsibility which is likely to follow from exchanges to which individuals have a voluntary, identified personal resource commitment is harder to generate when that commitment is relatively remote and ultimately involuntary, as is the case with public expenditure, which analytically is a political redistribution of resources backed by coercion. ${ }^{40}$ To identify coercion as essential to public expenditure does not, of course, mean that all public expenditure is illegitimate. There are overwhelmingly powerful arguments that interventionist public expenditures guided by collective decision-making may often maximise welfare. One of these arguments is that markets themselves can often function unacceptably poorly.

If an economic actor is asked whether he or she would like to be provided with a good without incurring the costs of its provision, then it is, of course, rational to reply with an unqualified yes. But it would be wrong to say that the actor chooses the good in such a case. The point is that no choice is involved. Liability insurance is based on making remote the connection between being provided with a good and bearing the cost of it, for the cost is, in the first instance, borne by a third party. This not only is an incentive to fraud, but it works against responsible choice. I want to put to one side the mixture of good and bad reasons for the current law and practice of liability insurance which emerge from the history of negligence liability and ask what we should do faced with the personal injury system we have now.

There is nothing fundamentally novel in the substance of what I will now say and I can therefore be very brief. If we want to find out what common citizens would do about the risk of personal injury caused by the negligence of another, we should abolish the existing law of personal injury caused by negligence and leave it to those citizens to buy first party insurance

\footnotetext{
${ }^{40}$ G Myrdal The Political Element in the Development of Economic Theory (London: Routledge and Kegan Paul, 1953) ch 7.
} 
cover, above a floor of adequate social security, ${ }^{41}$ if they so wish. Adopting such a policy is, in my opinion, possible only if retail insurance markets work tolerably well, and recent evidence of the performance of vital financial markets may lead one to conclude that such adoption therefore is impossible. ${ }^{42}$ Certainly, any reform intended to create a market in this area cannot be seen as deregulation but must involve extensive re-regulation by government. ${ }^{43}$ But we nevertheless can say that a first party insurance market would in principle reveal the preferences of common citizens in a way which liability insurance in principle simply cannot do. ${ }^{44}$

I myself do not believe that the choices of common citizens, mediated by first party insurance, would yield anything like the results of the existing law of negligence leading to liability insurance. In particular, whilst one can readily envisage the sufficiently highly paid insuring against loss of earnings, I do not believe that any insurance market whatsoever would emerge for protection against the risk of non-pecuniary loss, and this would, given the situation described by Lewis and Morris, amount to the abolition of the personal injury

\footnotetext{
${ }^{41}$ A comment on a draft of this paper by Professor Lewis leads me to emphasise at this point that I write this paper as a socialist whose main criticism of the personal injury system is that its existence makes rational and just welfare provision for incapacity impossible: Harris et al, above n 23, 449-61. My thinking relies heavily on the criticisms of the existing personal injury system by those, represented in the UK by Lewis, who postulate a welfarist alternative something like the New Zealand scheme, but I cannot agree with their making what seems to me to be an indefensible special case for accidents.

${ }^{42}$ Behind the question of how well insurance markets conceived along broadly conventional lines operate or could plausibly be made to operate lies the more profound question of how far such markets represent the optimum range of institutions for handling risks not borne publicly. The legal literature has recently been comprehensively reviewed (albeit the focus is on US materials) in LA Fennell, 'Unbundling Risk' (2011) 60 Duke Law Journal 1285. I will not discuss this at all.

${ }^{43} \mathrm{R}$ Abel 'General Damages are Incoherent, Incalculable, Incommensurable and Inegalitarian (But Otherwise a Great Idea)’ (2006) 55 DePaul Law Review 253, 324: 'If people really value general damages enough that they want to insure them, the state should correct the market imperfections that prevent this and, as a last resort, sell such loss insurance itself'. I cannot, on this particular occasion, resist breaking my self-denying ordinance about exploring the history of the discussion of the issues by pointing to Beveridge's 1942(!) discussion of the ways in which the state might, 'by regulation, by financial assistance or by itself undertaking the organisation of voluntary insurance', set the framework for the provision of first party insurance, in part to ensure 'that in buying life assurance persons of limited means should be guided by advice from a seller which is wholly disinterested': Beveridge, above n 3, paras 375, 188.

${ }^{44}$ Very considerable confusion has been created because the views of Judge Posner (and Professor Landes) on negligence are typically identified with 'the market': WS Landes and RA Posner, The Economic Structure of Tort Law (Cambridge, MA: Harvard University Press, 1987) chs 3-5. Their reasoning for a negligence regime, based on Posner's concept of wealth maximisation, is in fact an alternative to allocating goods by voluntary exchange: D Campbell, 'Welfare Economics for Capitalists: The Economic Consequences of Judge Posner' (2012) 33 Cardozo Law Review 2233, 2261-65.
} 
system in anything like its current form. ${ }^{45}$ Putting fraud to one side, it is now only rational for an economic actor to take any opportunity to seek what is called compensation for nonpecuniary loss. But such an actor would not pay for this opportunity. No rational economic actor will pay the premium for insurance that serves little or no purpose. ${ }^{46}$ I do not believe that common citizens would choose to pay for most of what is now provided by the personal injury system were the burden of choice made actual.

I could, of course, be wrong about this. But the time for speculation or policy-making on behalf of, rather than by, common citizens is long since past, and it is for this reason that I think interpersonal justice as I have interpreted it valuably highlights the essential issue, which is not whether the personal injury system compensates or deters, but whether it can claim to rest on the views of common citizens. But whilst it is not implausible to say that common citizens would subscribe to an effective system of payment for moral wrongdoing, it is utterly implausible to say that this means that common citizens subscribe to the existing personal injury system, for that system does not work as an economical, effective or efficient system of payment for moral wrongdoing at all, nor can it possibly do so. We could test this by creating a proper market in personal injury liability, but we do not do so.

If one is trying to give effect to the voluntary choices of economic actors, it is wrong in principle to begin by comparing the results of loss and liability insurance systems from the sub specie aeternitatis position of the theoretical economic planner. I say this with the greatest hesitation as this is the very position adopted in Professor Clarke's introduction to insurance law, where perhaps the most influential single British comparison of the merits of loss and liability insurance concludes that:

\footnotetext{
${ }^{45}$ A comment on a draft of this paper by Professor Murphy leads me to say that my point is not that liability insurance is currently unattractive to insurers, though it seems it is (C Parsons 'Moral Hazard in Liability Insurance' (2003) 28 Geneva Papers on Risk and Insurance 448). It is that a first party insurance market in nonpecuniary loss would be completely unattractive to premium payers.

${ }^{46}$ I believe that my point survives the pointing out of the incontrovertible fact that deceiving customers into doing exactly this has been a large part of the business of the financial services industry since the Big Bang.
} 
the issue is difficult ... the debate has no clear winner ... any general conclusions for loss insurance and liability insurance are suspect ... perhaps the Australian judge, who said that the merits of loss insurance should not be assumed but should be tested in each situation, was right. ${ }^{47}$

Well, test it then. It is not a test for the state to impose specific forms of third party liability (which of necessity have a chilling effect on first party insurance). If Clarke's argument that it is hard to know what to do is right, as to some considerable degree I believe it is, then surely this is an argument for the state not to intervene as it does not know what to do. It tells us something about policy-making in this area, as in so many areas, that not knowing what to do is taken to be a reason for intervention when this is a very powerful reason not to intervene.

\section{CONCLUSION: THE JUSTICE OF CHOICE}

Much tort scholarship proceeds in blithe disregard of the way the actual remedy provided in personal injury cases almost completely contradicts the abstract remedy assumed by such scholarship. When the discussion is moved to what I have called the meta-doctrinal plane of overt consideration of corrective justice or of civil recourse, the unreal quality of the discussion is generally but little diminished as the law in action barely approximates to the still abstract claims being made. The concept of interpersonal justice central to Professor Robertson's discussion of the role of policy in the law of negligence is meta-doctrinal in this way, but I have wrenched the concept away from his use in order to ask whether we can possibly conclude that the personal injury system is based on common citizens' beliefs about interpersonal justice. If we could reach this conclusion, this would not make the personal injury system just, in my opinion, for it would still be open to much criticism, but it would

\footnotetext{
${ }^{47} \mathrm{M}$ Clarke Policies and Perceptions of Insurance Law in the Twenty First Century (Oxford: Clarendon Press, rev edn, 2007) 330. The dicta cited was that of Stephen J in Caltex Oil (Aust) Pty Ltd v Dredger 'Wilhelmstad' (1976) 11 ALR 227 (High Court of Australia) at 265. I hope not to put words in his mouth when I claim that Clarke effectively admits the argument I seek to make generally for some specific commercial situations: loc cit, 330-31.
} 
make it justified, and such criticism would not ground abolition but would have to be used in an attempt to make common citizens change their beliefs.

It is not a criticism of the law of negligence underpinning the personal injury system to say that it mediates common citizens' views. All law mediates in this sense as no law could or ever should give unconsidered expression to those views. But it is, or should be, a very telling criticism of the law of negligence that the form of mediation of views about the response to personal injury to which it has necessarily given rise, essentially general liability insurance, makes the personal injury system work in a way which almost completely contradicts the universal justification for that system, that there is a class of moral wrongdoing for which the offender must pay. Such a system can exist only because it is not chosen by common citizens but is imposed on them by legal compulsion, and this is indeed the case. As it happens, liability insurance is almost entirely directly compulsory in the UK, ${ }^{48}$ but this is less important than the way that the law of negligence, even when it is not explicitly compulsory, is, as I have mentioned above, compulsory in the sense that it is the product of decisions made principally by the courts about the liability that common citizens as neighbours must compulsorily bear.

There is a form of institutional mediation of citizens' views that would, I believe, in principle much more accurately reflect those views. This would be the construction of a first party system of insurance against personal injury above a social security floor. The current climate of justifiable extreme scepticism about the operation of financial markets (and, to a lesser but itself substantial extent, about the provision of social security) rightly gives added weight to concerns that a voluntary market in personal injury insurance would be

\footnotetext{
${ }^{48}$ In the UK, $80 \%$ of claims are motor accident claims and $8 \%$ of claims are employer liability claims. Insurance is legally compulsory in both areas. There is a full account of the compulsory duties to insure in this sense in R Merkin and and S Dziobon ‘Tort Law and Compulsory Insurance' in Arvind and Steele (eds), above n 25 and Merkin and Steele, above n 33, 257-60. It would not, in my opinion, unduly stretch this more direct sense of compulsory to describe the forms of provision for negligence claims by public authorities in this way, and, to move to an essentially similar issue, also to include medical malpractice in the NHS.
} 
unacceptably defective. But, nevertheless, the legitimacy of the market economies rests on their giving effect to actual voluntary choice in a way which is superior to any other form of general economy, and moving to other forms of allocative mechanism backed by coercion requires justification of that coercion in precisely the way that advocacy of the personal injury system avoids. It is trite to say that rational debate is necessary, but it is necessary to say that rational debate is what we do not have because it is just what the law of negligence cannot yield.

If construction of general first party insurance led to the effective abandonment of the personal injury system, as I am certain it would, this should not necessarily be taken as the failure of the insurance market. I believe this would reflect the fact that the good of security against personal injury in anything like its current form would not be seen as worthwhile by those conscious of having to pay for it in the way which is essential to actual economic choice. Preventing the recognition that there are a multitude of benefits which should not be provided because they are not worth their cost is, it seems, a central feature of the compensation culture. 